\title{
Níveis Dietéticos de Lisina para Frangos de Corte de 1 a 21 e 22 a 40 Dias de Idade ${ }^{1}$ Fernando Guilherme Perazzo Costa 2 , Horacio Santiago Rostagno ${ }^{3}$, Luiz Fernando Teixeira Albino ${ }^{3}$, Paulo Cezar Gomes ${ }^{3}$, Rodrigo Santana Toledo ${ }^{4}$
}

\begin{abstract}
RESUMO - Foram realizados dois experimentos para determinar a exigência nutricional de lisina total para frangos de corte Ross de ambos os sexos, nos períodos de 1 a 21 e 22 a 40 dias de idade, respectivamente. Foram avaliados o ganho de peso, consumo de ração, conversão alimentar e avaliação de carcaça. Para cada experimento, o delineamento utilizado foi o inteiramente casualizado, em esquema fatorial 2x6, constituídos de dois sexos e seis níveis dietéticos de lisina, com seis repetições e um total de 1440 aves. As dietas basais com $1,03 \%$ de lisina total, $22,00 \% \mathrm{~PB}$ e $3000 \mathrm{kcal} \mathrm{EM} / \mathrm{kg}$, no primeiro experimento, e $0,92 \%$ de lisina total, 20,00\% PB e $3150 \mathrm{kcal}$ EM/ $\mathrm{kg}$ no segundo experimento, foram suplementadas com seis níveis de lisina pura $(0 ; 0,06 ; 0,12 ; 0,18 ; 0,24$ e $0,30 \%)$. Considerando-se os dados de ganho de peso e conversão alimentar, as exigências nutricionais estimadas para o experimento de 1 a 21 dias foram 1,303 e $1,249 \%$ de lisina total e 1,183 e 1,129\% de lisina digestível, para os machos e fêmeas, respectivamente. Para o experimento de 22 a 40 dias, levando em consideração os parâmetros analisados de desempenho e avaliação de carcaça, pode-se estimar uma exigência de 1,164 e 1,143\% de lisina total e 1,044 e 1,023\% de lisina digestível para machos e fêmeas Ross, respectivamente.
\end{abstract}

Palavras-chave: avaliação de carcaça, exigência nutricional, frangos de corte, lisina total

\section{Dietary Lysine Levels for Broilers Chickens from 1 to 21 and 22 to 40 Days of Age}

\begin{abstract}
Two experiments were carried out to determine the nutritional requirement of total lysine for Ross broiler chickens from one to 21 and 22 to 40 days of age, of both sexes. The parameters evaluated were weight gain, feed intake, feed conversion and carcass evaluation. In each experiment, a completely randomized experimental design, in a 2 x 6 (two sexes and six dietary lysine levels) factorial arrangement with six replicates, using a total of 1440 birds, was used. The basal diets with $1.03 \%$ total lysine, $22.0 \% \mathrm{CP}$ and $3000 \mathrm{kcal} \mathrm{ME} / \mathrm{kg}$ in the first experiment and $0.92 \%$ total lysine, $20.0 \% \mathrm{CP}$ and $3150 \mathrm{kcal} \mathrm{ME} / \mathrm{kg}$ in the second experiment, suplemented with six levels pure lysine $(0.0 ; 0.06 ; 0.12 ; 0.18 ; 0.24$ and $0.30 \%)$, were used. Considering weigth gain and feed conversion, the dietary requirement estimates for the experiment from 1 to 21 days were 1.303 and $1.249 \%$ total lysine and 1.183 and $1.129 \%$ digestible lysine for males and females, respectively. For the experiment from 22 to 40 days, the performance and evaluation carcass values were 1.164 and $1.143 \%$ total lysine and 1.044 and $1.023 \%$ digestible lysine for males and females, respectively.
\end{abstract}

Key Words: broiler chickens, carcass evaluation, nutritional requirement, total lysine

\section{Introdução}

A nutrição animal é uma das ciências que mais tem sido desenvolvida neste século. Eas aves, principalmente os frangos de corte, são o modelo experimental mais utilizado para a avaliação das pesquisas nutricionais. No entanto, com todos os conhecimentos até hoje acumulados, aindaé difícil compartilhar a evolução dos conhecimentos nutricionais com os avanços genéticos, com as práticas de manejo, com os problemas sanitários, com a variável ambiental e também com os aspectos de competitividade mercadológico.

A lisina é um aminoácido de referência nos estudos nutricionais, não só por ser o segundo aminoácido limitante, depois da metionina, mas também porque ele é mais fácil de ser analisado do que a metionina, e especialmente do que a cistina. Outro fator, é de que a lisina é utilizada somente para o aumento da deposição da proteína corporal e manutenção, não estando envolvida em outros processos metabólicos.

Torna-se difícil definir os requerimentos de aminoácidos das aves quando se sabe que eles são influenciados por uma série de fatores, tais como, densidade calórica e populacional, teor de proteína na ração, linhagem, condições ambientais e estado sanitário dos animais, além de que, a digestibilidade e a disponibilidade dos nutrientes podem variar entre os alimentos (BERCOVICI, 1998). No entanto,

\footnotetext{
1 Parte da tese apresentada à Universidade Federal de Viçosa para a obtenção do título de "Doctor Science".

2 Professor do Departamento de Zootecnia da UFPB, Areia-PB. E.mail: fperazzo@cca.ufpb.br

3 Professor do Departamento de Zootecnia da UFV, Viçosa-MG. E.mail: rostagno@mail.ufv.br

4 Aluno do curso de Pós-Graduação da UFV, Viçosa-MG.
} 
ROSTAGNO e PACK (1995) demonstraram que as aves alimentadas com aminoácidos digestíveis, apresentaram melhor ganho de peso, melhor conversão alimentar e maiores benefícios econômicos em relação às rações formuladas à base de aminoácidos totais.

A exigência de lisina $(1,1 \%)$ para aves de 0 a 3 semanas de idade sugerido pelo NATIONAL RESEARCH COUNCIL - NRC (1994) é adequado para obter o máximo crescimento e bom consumo alimentar, mas o nível de $1,07 \%$ de lisina digestível ( $1,17 \%$ total $)$ é exigido para maximizar a conversão alimentar (KNOWLES et al., 1997). Também BARBOZA e ROSTAGNO (1998a) estimaram uma exigência média de $1,198 \%$ de lisina para a fase de 1 a 21 dias de idade. De acordo com BILGILI et al. (1992), o aumento da ingestão de lisina acima do nível exigido para máximo ganho de peso interfere na composição corporal pelo acréscimo do rendimento de peito e pela diminuição da porcentagem de gordura abdominal. MACK et al. (1999) afirmaram que o nível ótimo para conversão alimentar de frangos de corte machos Ross criados no período de 20 a 40 dias foi de $1,22 \%$ para lisina total $(1,15 \%$ de lisina digestível), recomendando a relação ideal de aminoácidos em relação à lisina de 75\% para $\mathrm{Met}+\mathrm{Cis}$, 63\% para Treonina, 19\% para Triptofano, 112\% para Arginina, $71 \%$ para Isoleucina e $81 \%$ para Valina. Embora o crescimento e a eficiência alimentar sejam constantemente observados em dietas com níveis normais de proteína (SUMMERS e LEESON, 1995), a suplementação com aminoácidos melhora a qualidade da carcaça (FANCHER e JENSEN, 1989), notadamente o rendimento do músculo do peito.

Considerando que a determinação da exigência de lisina é um fator de grande importância para a moderna avicultura de linhagem de alto desempenho, este trabalho teve como objetivo determinar a exigência de lisina na ração para frangos de corte machos e fêmeas Ross, sobre o desempenho e avaliação de carcaça, nas fases inicial e crescimento.

\section{Material e Métodos}

Dois experimentos foram conduzidos no setor de Avicultura do Departamento de Zootecnia, do Centro de Ciências Agrárias da Universidade Federal de Viçosa. Para cada experimento, foram utilizados 1440 aves de corte, da linhagem Ross, sendo metade de cada sexo, distribuídas num delineamento experimental inteiramente casualizado, em esquema fatorial $2 \times 6$, constituído de
Tabela 1 - Composição percentual da dieta basal Table 1 - Percentage composition of the basal diet

\begin{tabular}{|c|c|c|}
\hline \multirow[t]{2}{*}{$\begin{array}{l}\text { Ingredientes (\%) } \\
\text { Ingredients (\%) }\end{array}$} & \multicolumn{2}{|c|}{$\begin{array}{l}\text { Experimento } \\
\text { Experiment }\end{array}$} \\
\hline & $\begin{array}{l}\text { 1-21 dias } \\
\text { days }\end{array}$ & $\begin{array}{l}22-40 \text { dias } \\
\quad \text { days }\end{array}$ \\
\hline Milho & 43,262 & 52,853 \\
\hline $\begin{array}{l}\text { Corn } \\
\text { Sorgo }\end{array}$ & 15,000 & 9,000 \\
\hline $\begin{array}{l}\text { Sorghum } \\
\text { Farelo de Soja } 46 \%\end{array}$ & 29,000 & 25,137 \\
\hline $\begin{array}{l}\text { Soybean meal } \\
\text { Farelo de glúten de milho } 60 \% \\
\text { Corn gluten meal }\end{array}$ & 6,000 & 5,000 \\
\hline $\begin{array}{l}\text { Óleo de soja } \\
\text { Soybean meal }\end{array}$ & 2,060 & 3,651 \\
\hline $\begin{array}{l}\text { Fosfato bicálcico } \\
\text { Dicalcium phosphate }\end{array}$ & 1,840 & 1,660 \\
\hline $\begin{array}{l}\text { Calcário } \\
\text { Limestone }\end{array}$ & 1,180 & 1,100 \\
\hline $\begin{array}{l}\text { Suplemento Vit. Min. e Aditivos* } \\
\text { Supplement vitamin mineral additive }\end{array}$ & 0,390 & 0,315 \\
\hline $\begin{array}{l}\text { DL - Metionina } 99 \% \\
\text { DL-Methionine }\end{array}$ & 0,208 & 0,211 \\
\hline $\begin{array}{l}\text { L-Arginina HCL } \\
L \text {-Arginine } H C L\end{array}$ & 0,130 & 0,167 \\
\hline $\begin{array}{l}\text { L-Treonina } \\
\text { L-Threonine }\end{array}$ & 0,030 & 0,006 \\
\hline $\begin{array}{l}\text { Amido } \\
\text { Starch }\end{array}$ & 0,500 & 0,500 \\
\hline $\begin{array}{l}\text { Sal } \\
\text { Salt }\end{array}$ & 0,400 & 0,400 \\
\hline $\begin{array}{l}\text { Total } \\
\text { Composição }\end{array}$ & 100,000 & 100,000 \\
\hline Composition & & \\
\hline $\begin{array}{l}\text { Energia metabolizável }(\mathrm{kcal} \mathrm{EM} / \mathrm{kg})^{1} \\
\text { Metabolizable energy }\end{array}$ & 3000 & 3150 \\
\hline $\begin{array}{l}\text { Proteína bruta }(\%)^{2} \\
\text { Crude protein }\end{array}$ & 22,00 & 20,00 \\
\hline $\begin{array}{l}\text { Crude protein } \\
\text { Lisina }(\%)^{1}\end{array}$ & 1,03 & 0,92 \\
\hline $\begin{array}{l}\text { Lysine } \\
\text { Lisina digestível }{ }^{1}\end{array}$ & 0,91 & 0,80 \\
\hline $\begin{array}{l}\text { Lysine digestible } \\
\text { Lisina }(\%)^{2} \\
\text { Lysine }\end{array}$ & 1,02 & 0,95 \\
\hline $\begin{array}{l}\text { Metionina }+ \text { cistina }(\%)^{2} \\
\text { Methionine }+ \text { cystine }\end{array}$ & 0,92 & 0,88 \\
\hline $\begin{array}{l}\text { Treonina }(\%)^{2} \\
\text { Threonine }\end{array}$ & 0,88 & 0,80 \\
\hline $\begin{array}{l}\text { Arginina }(\%)^{2} \\
\text { Arginine }\end{array}$ & 1,42 & 1,33 \\
\hline $\begin{array}{l}\text { Fósforo disponível }(\%)^{1} \\
\text { Available phosphorus }\end{array}$ & 0,45 & 0,41 \\
\hline $\mathrm{Ca}(\%)$ & 1,00 & 0,91 \\
\hline
\end{tabular}

* Níveis de suplementação de vitaminas, minerais e aditivos, quantidade por $\mathrm{kg} / \mathrm{ração}$ (Suplementation vitamins, minerals and additives levels, amount by kg/feed): Vit. A, 10000 UI; Vit. $D_{3}, 2000$ UI; Vit. E, 30 Ul; Vit. $B_{1}, 2$ mg; Vit. B, 3 mg; Vit. B $12,0,015$ mg; Ac. Pantotênico (Pantotenic acid), $12 \mathrm{mg}$; Biotina (Biotin), 0,1 g; Vit. $\mathrm{K}_{3}, 3 \mathrm{mg}$; Ácido fólico (Folic acid), $1 \mathrm{mg}$; Ácido nicotínico (Nicotinic acid), 50 mg; Coccidiostático (Coccidiostatic), $66 \mathrm{mg}$ (Coxistac 12); Stafac 20, $15 \mathrm{mg}$; Cloreto de colina $60 \%$ (Choline choride), $6 \mathrm{mg}$; Antioxidante (Antioxidant), $1 \mathrm{mg}$ (BHT); Selênio (Selenium), 0,25 mg; Manganês (manganese), $106 \mathrm{mg}$; Ferro (Iron), $100 \mathrm{mg}$; Cobre (Copper), $20 \mathrm{mg}$; Cobalto (Cobalt), $2 \mathrm{mg}$; lodo (lodine), $2 \mathrm{mg}$; excipiente q.s.p., $1000 \mathrm{~g}$.

1 Valores calculados de acordo com ROSTAGNO et al. (2000) (Values

calculated in agreement with ROSTAGNO et al., 2000)

2 Valores analisados no Laboratório Eurolysine - Paris (França) (Values analyzed in the Eurolysine Lab - Paris, France). 
dois sexos e seis níveis de lisina, com seis repetições por tratamento e 20 aves por unidade experimental.

Utilizou-se uma dieta basal deficiente em lisina (Tabela 1), contendo 22,00\% PB, $3000 \mathrm{kcal} \mathrm{EM} / \mathrm{kg}$ e $1,03 \%$ de lisina total, suplementada com seis níveis de lisina pura $(0,0 ; 0,06 ; 0,12 ; 0,18 ; 0,24$ e $0,30 \%)$, correspondendo aos níveis de 1,$03 ; 1,09 ; 1,15 ; 1,21$; 1,27 e $1,33 \%$ de lisina total nas dietas para o experimento de 1 a 21 dias de idade. No experimento de 22 a 40 dias, as rações eram compostas de $20,00 \%$ PB, $3150 \mathrm{kcal} \mathrm{EM} / \mathrm{kg}$ e os níveis de lisina total na ração foram 0,$92 ; 0,98 ; 1,04 ; 1,10 ; 1,16$ e 1,22\%. Para o experimento de 1 a 21 dias, o peso inicial das aves foi de 37,0 g para ambos os sexos, enquanto que para o experimento de 22 a 40 dias, o peso inicial foi de 698,7 e 662,5 g para machos e fêmeas, respectivamente. As exigências nutricionais mínimas, exceto para lisina, foram atendidas segundo as recomendações de ROSTAGNO et al. (1996) e as suplementações com L-Lisina HCL (99\%), contendo 79,2\% de lisina, considerando-a com $100 \%$ de digestibilidade verdadeira (LECLERCQ, 1998), foram realizadas em substituição ao amido do milho na ração. As aves utilizadas no experimento de 22 a 40 dias de idade, foram criadas até os 21 dias de idade, em galpão a parte, e submetidas a um manejo convencional.

Ao final de cada experimento, foram avaliados o consumo de ração (CR), ganho de peso (GP), conversão alimentar (CA) e para o experimento de 22 a 40 dias, foram abatidas quatro aves de cada unidade experimental para ser feita a avaliação de carcaça (rendimento de carcaça, cortes nobres e gordura abdominal).

As análises estatísticas desses parâmetros foram realizadas de acordo com o programa Sistema para Análises Estatísticas e Genética (SAEG), desenvolvido na UNIVERSIDADE FEDERAL DE VIÇOSA - UFV (1997) ea estimativa das exigências em lisina, estabelecida por meio de modelos de regressão linear e quadrática.

\section{Resultados e Discussão}

Níveis de lisina da ração no desempenho de frangos de corte o período de 1 a 21 dias de idade

A mortalidade durante todo o período experimental foi de $0,83 \%$, sem efeito significativo sobre os tratamentos. Não houve efeito $(\mathrm{P}>0,05)$ dos níveis de lisina sobre o consumo de ração das fêmeas, exceto para os machos que responderam linearmente $(\mathrm{P}<0,05)$. Quanto às fêmeas, estes resultados foram semelhantes aos obtidos por WALDROUP et al.
(1976) e COLNAGO e JENSEN (1992). Como pode ser visto na Tabela 2, os níveis de lisina influenciaram de forma quadrática o ganho de peso e a conversão alimentar das aves, independente do sexo, o que confirma os resultados obtidos por HAN e BAKER (1991, 1992), CONHALATO (1998) e BARBOZA e ROSTAGNO (1998a).

As estimativas das exigências nutricionais para frangos de corte de um a 21 dias de idade, considerando-se os dados de ganho de peso e conversão alimentar são apresentadas na Tabela 3 , sendo que as equações que apresentam melhores ajustes foram obtidas com o modelo quadrático.

Pode-se verificar um efeito quadrático $(\mathrm{P}<0,05)$ dos níveis de lisina sobre o ganho de peso, apresentando uma exigência nutricional de $1,285 \%$ para os machos e 1,236\% para as fêmeas. Conclui-se que os machos tiveram melhor ganho de peso, o que está de acordo com os valores obtidos por HAN e BAKER (1992) e BARBOSA et al. (1998).

Com relação à conversão alimentar, foi observado efeito quadrático dos níveis de lisina para machos $(\mathrm{P}<0,01)$ e fêmeas $(\mathrm{P}<0,05)$, com exigências nutricionais de 1,303 e 1,249\% de lisina total, respectivamente. Estes resultados estão acima do utilizado pelas empresas de integração e a indústria brasileira de ração, descrito por LIMA (1996), quando diz que a exigência de lisina neste período está na faixa de 1,05 a $1,20 \%$.

Levando em consideração os melhores valores absolutos obtidos, são recomendados os níveis de 1,303 e $1,249 \%$ de lisina total, o que corresponde a 1,183 e $1,129 \%$ de lisina digestível, para machos e fêmeas, respectivamente.

Níveis de lisina da ração no desempenho e avaliação de carcaça de frangos de corte no período de 22 a 40 dias de idade

Diante dos dados de desempenho expostos na Tabela 2, observou-se efeito quadrático $(\mathrm{P}<0,01)$ dos níveis de lisina sobre o ganho de peso e a conversão alimentar dos machos. Nas fêmeas, observou-se efeito quadrático $(\mathrm{P}<0,01)$ para conversão alimentar.

As equações de regressão, baseadas nos resultados de desempenho, com as respectivas exigências estimadas, encontram-se na Tabela 3 . O consumo de ração apresentou efeito linear $(\mathrm{P}<0,01)$ para as fêmeas, enquanto os machos não foram influenciados pelos níveis de lisina estudados, estando estes resultados de acordo com os obtidos por REZENDE et al. (1980) e BARBOZA e ROSTAGNO (1998b). A 
Tabela 2 - Efeito dos níveis de lisina sobre o desempenho de frangos de corte Ross, machos e fêmeas, nos experimento de 1 a 21 e 22 a 40 dias de idade

Table 2 - Effect of lysine levels on the performance males and females of broiler chickens Ross from 1 to 21 and 22 to 40 days of age

\begin{tabular}{|c|c|c|c|c|c|c|}
\hline \multirow[t]{2}{*}{$\begin{array}{l}\text { Níveis de lisina }(\%) \\
\text { Levels lysine }\end{array}$} & \multicolumn{2}{|c|}{$\begin{array}{c}\text { Consumo de ração }(\mathrm{g}) \\
\text { Feed intake }\end{array}$} & \multicolumn{2}{|c|}{$\begin{array}{c}\text { Ganho de peso }(\mathrm{g}) \\
\text { Weight gain }\end{array}$} & \multicolumn{2}{|c|}{$\begin{array}{c}\text { Conversão alimentar }(\mathrm{g} / \mathrm{g}) \\
\text { Feed:gain ratio }\end{array}$} \\
\hline & M & $\mathrm{F}$ & $\mathrm{M}$ & $\mathrm{F}$ & $\mathrm{M}$ & $\mathrm{F}$ \\
\hline \multicolumn{7}{|l|}{$1-21$ dias (days) } \\
\hline $\begin{array}{l}1,03 \\
109\end{array}$ & 938 & $\begin{array}{l}902 \\
025\end{array}$ & 611 & 592 & 1,533 & $\begin{array}{l}1,532 \\
1481\end{array}$ \\
\hline $\begin{array}{l}1,09 \\
1,15\end{array}$ & $\begin{array}{l}964 \\
963\end{array}$ & $\begin{array}{l}925 \\
895\end{array}$ & $\begin{array}{l}644 \\
680\end{array}$ & $\begin{array}{l}624 \\
633\end{array}$ & $\begin{array}{l}1,498 \\
1,414\end{array}$ & $\begin{array}{l}1,481 \\
1,414\end{array}$ \\
\hline 1,21 & 984 & 891 & 707 & 643 & 1,392 & 1,385 \\
\hline 1,27 & 982 & 889 & 711 & 634 & 1,381 & 1,401 \\
\hline 1,33 & 975 & 896 & 706 & 636 & 1,382 & 1,409 \\
\hline Média & 968 & 900 & 676 & 628 & 1,423 & 1,435 \\
\hline \multicolumn{7}{|l|}{ Mean } \\
\hline Regressão & $\mathrm{L}^{*}$ & NS & $\mathrm{Q}^{* *}$ & $\mathrm{Q}^{* *}$ & $\mathrm{Q}^{* *}$ & $\mathrm{Q}^{* *}$ \\
\hline Regression & & & & & & \\
\hline CV $(\%)$ & \multirow{2}{*}{\multicolumn{2}{|c|}{3,85}} & \multirow{2}{*}{\multicolumn{2}{|c|}{4,44}} & \multirow{2}{*}{\multicolumn{2}{|c|}{3,30}} \\
\hline $22-40 \operatorname{dias}$ (days) & & & & & & \\
\hline 0,92 & 2820 & 2420 & 1384 & 1160 & 2,040 & 2,090 \\
\hline 0,98 & 2850 & 2390 & 1446 & 1170 & 1,970 & 2,040 \\
\hline 1,04 & 2870 & 2340 & 1514 & 1180 & 1,900 & 1,980 \\
\hline 1,10 & 2800 & 2340 & 1493 & 1170 & 1,880 & 2,000 \\
\hline 1,16 & 2850 & 2310 & 1511 & 1160 & 1,880 & 1,990 \\
\hline 1,22 & 2780 & 2310 & 1490 & 1160 & 1,870 & 1,980 \\
\hline Média & 2830 & 2350 & 1470 & 1170 & 1,920 & 2,010 \\
\hline \multicolumn{7}{|l|}{ Mean } \\
\hline Regressão & NS & $\mathrm{L}^{*}$ & $\mathrm{Q}^{* *}$ & NS & $\mathrm{Q}^{* *}$ & $\mathrm{Q}^{* *}$ \\
\hline Regression & \multirow{2}{*}{\multicolumn{2}{|c|}{2,29}} & \multirow{2}{*}{\multicolumn{2}{|c|}{2,83}} & \multirow{2}{*}{\multicolumn{2}{|c|}{2,06}} \\
\hline CV $(\%)$ & & & & & & \\
\hline
\end{tabular}

$L^{*}-\quad$ Efeito linear $(P<0,05),\left(L^{*}-\right.$ Linear effect $(P<.05)$.

$Q^{* *}$ - Efeito quadrático $(P<0,01), Q^{* *}$ (Quadratic effect $(P<.01)$.

NS - Não significativo (Not significant).

M - Macho (Male), F - Fêmea (Female).

redução no consumo de ração observada pelos autores citados anteriormente pode ter ocorrido em razão de possível melhora gradativa na relação entre a lisina e os demais aminoácidos da dieta basal. Como sugerido por Harper (1976), citado por CABEL et al. (1988), os aminoácidos presentes em uma ração podem alterar o perfil aminoacídico plasmático e regular o balanço energético do animal. Em rações desbalanceadas, o mecanismo que regula o consumo pode estar modificado, podendo ocorrer aumento na ingestão de alimento, em resposta a alterações no metabolismo energético ou em resposta à demanda crescente dos aminoácidos na ração. Em relação a este mesmo parâmetro, alguns pesquisadores como CONHALATO (1998) e HAN e BAKER (1994) verificaram efeito quadrático, discordando do ocorrido nesta pesquisa. Com relação à conversão alimentar, constatou-se melhora $(\mathrm{P}<0,01)$ até o nível de 1,164 e $1,143 \%$ de lisina total, correspondente a um consumo estimado de 33,14 e 26,75 g de lisina para machos e fêmeas, respectivamente. Convertendo estas exigências para o nível de $1000 \mathrm{kcal} \mathrm{EM} / \mathrm{kg}$ de ração, obteve-se 0,364 e 0,357\% de lisina / Mcal EM para machos e fêmeas, respectivamente. Estes resultados confirmam a hipótese de melhora no perfil aminoacídico da ração com o aumento do nível de lisina anteriormente relatado. Comparando com alguns autores, esta exigência está acima dos experimentos realizados por BARBOZA e ROSTAGNO (1998b), semelhante a $1,15 \%$ de lisina digestível verificado por MACK et al. (1999). Estes resultados indicam também que os machos foram mais eficientes que as fêmeas, concordando dessa maneira, com HAN e BAKER (1994) e MORAN e BILGILI (1990). Analisando os resultados de desempenho, pode-se deduzir que o maior ganho de peso obtido para machos no nível de $1,04 \%$ de lisina total, ocorreu em razão do aumento no consumo de ração até este nível. Os resultados de desempenho verificados durante esse período, estão em conformidade com 
Tabela 3 - Estimativas das exigências de lisina e regressões para as variáveis ganho de peso e conversão alimentar, considerando o percentual de lisina na dieta para frangos de corte, no experimento de 1 a 21 e 22 a 40 dias de idade

Table 3 - Estimates of lysine requirements and regressions for weight and feed:gain ratio, according to the lysine percent in the diet for broiler chickens from 1 to 21 and 22 to 40 days of age

\begin{tabular}{|c|c|c|c|}
\hline & $\begin{array}{c}\text { Exigência (\%) } \\
\text { Requirement }\end{array}$ & $\begin{array}{l}\text { Regressão } \\
\text { Regression }\end{array}$ & $\mathrm{r}^{2}$ \\
\hline & & $1-21$ dias (days) & \\
\hline & & $\begin{array}{l}\text { Machos } \\
\text { Males }\end{array}$ & \\
\hline \multirow{3}{*}{$\begin{array}{l}\text { Ganho de peso } \\
\text { Weight gain } \\
\text { Conversão alimentar } \\
\text { Feed:gain ratio }\end{array}$} & 1,285 & $y=-1920,23+4096,17 x-1594,27 x^{2}$ & 0,99 \\
\hline & 1,303 & $y=5,20113-5,87875 x+2,25970 x^{2}$ & 0,96 \\
\hline & & $\begin{array}{l}\text { Fêmeas } \\
\text { Female }\end{array}$ & \\
\hline \multirow{4}{*}{$\begin{array}{l}\text { Ganho de peso } \\
\text { Weight gain } \\
\text { Conversão alimentar } \\
\text { Feed:gain ratio } \\
\end{array}$} & 1,236 & $y=-1066,64+2768,03 x-1120,082 x^{2}$ & 0,94 \\
\hline & 1,249 & $y=5,88347-7,19087 x+2,87813 x^{2}$ & 0,96 \\
\hline & & $22-40$ dias (days) & \\
\hline & & $\begin{array}{c}\text { Machos } \\
\text { Males }\end{array}$ & \\
\hline \multirow{3}{*}{$\begin{array}{l}\text { Ganho de peso } \\
\text { Weight gain } \\
\text { Conversão alimentar } \\
\text { Feed:gain ratio }\end{array}$} & 1,125 & $y=-2346,09+6861,15 x-3048,54 x^{2}$ & 0,93 \\
\hline & 1164 & $y=580928-677354 x-291007 x^{2}$ & 097 \\
\hline & & $\begin{array}{l}\text { Fêmeas } \\
\text { Females }\end{array}$ & \\
\hline $\begin{array}{l}\text { Conversão alimentar } \\
\text { Feed:gain ratio }\end{array}$ & 1,143 & $4,83056-4,98888 x+2,18254 x^{2}$ & 0,89 \\
\hline
\end{tabular}

ROSTAGNO e PACK (1995) e HAN e BAKER (1994) que, observaram exigências de lisina maiores para conversão alimentar que para ganho de peso.

Os resultados de rendimento de carcaça (RC), rendimento de peito (RPT), rendimento de filé de peito (RFP) e gordura abdominal (GA) dos frangos de corte abatidos com 40 dias de idade são apresentados na Tabela 4 e as estimativas nutricionais de exigências de lisina, levando em consideração equações ajustadas por meio de modelos de regressão linear e quadrática, são apresentadas na Tabela 5 .

Para a variável rendimento de carcaça de machos, houve efeito linear $(\mathrm{P}<0,05)$, à medida que os níveis de lisina aumentaram, sendo esses valores superiores aos obtidos por WALDROUP (1991) e não similares aos obtidos por MORAN e BIGILI (1990); SCHEUERMANN et al. (1993) e KIDD et al. (1997). De acordo com SIBBALD e WOLYNETZ (1986), o requerimento de aminoácidos essenciais para máximo rendimento de carne de peito (RPT) está acima do considerado para crescimento e se- melhante ao obtido por HOLSHEIMER e VEERKAMP (1992). No entanto, neste trabalho, detectou-se melhora no RPT, com o aumento do nível de lisina na ração, o que não está de acordo com os resultados de HAN e BAKER (1994), que não verificaram melhora no RPT com altos níveis de lisina e metionina na ração. Para as variáveis RPT e RFP, as fêmeas apresentaram efeito quadrático, representado pelas equações $\mathrm{y}=-37,7388+129,277 \mathrm{x}-58,3047 \mathrm{x}^{2}$ e $y=-61,4748+154,954 x-69,547 x^{2}$, em que foi obtida exigência de 1,109 e $1,114 \%$ de lisina para máxima deposição de peito e filé de peito neste período, respectivamente. Em média, as fêmeas foram mais eficientes, pois tiveram maior rendimento de peito e filé de peito para menor nível de lisina na dieta. Esses resultados são coerentes com HICKLING et al. (1990), uma vez que a lisina tem grande participação na composição da proteína muscular. Embora o crescimento e a eficiência alimentar sejam constantemente observados em dietas com níveis normais de proteína (SUMMERS e LEESON, 1985), 
Tabela 4 - Efeito dos níveis de lisina sobre o rendimento de carcaça, cortes nobres e gordura abdominal, em percentagem, de machos e fêmeas, no período de 22 a 40 dias de idade

Table 4 - Effect of lysine on the carcass yield, nobles cuts and abdominal fat, in percentage, of males and females from 22 to 40 days of age

\begin{tabular}{|c|c|c|c|c|c|c|c|c|}
\hline \multirow[t]{2}{*}{$\begin{array}{l}\text { Níveis de lisina }(\%) \\
\text { Levels of lysine }\end{array}$} & \multicolumn{2}{|c|}{$\begin{array}{l}\text { Carcaça }(\%) \\
\text { Carcass }(\%)\end{array}$} & \multicolumn{2}{|c|}{$\begin{array}{c}\text { Peito com osso }(\%) \\
\text { Breast with bone }\end{array}$} & \multicolumn{2}{|c|}{$\begin{array}{l}\text { Filé de peito }(\%) \\
\text { Breast fillet }\end{array}$} & \multicolumn{2}{|c|}{$\begin{array}{c}\text { GA }(\%) \\
\text { Abdominalfat }\end{array}$} \\
\hline & $\mathrm{M}$ & $\mathrm{F}$ & $\mathrm{M}$ & $\mathrm{F}$ & $\mathrm{M}$ & $\mathrm{F}$ & $\mathrm{M}$ & $\mathrm{F}$ \\
\hline 0,92 & 65,37 & 66,75 & 31,72 & 31,66 & 22,69 & 22,00 & 2,37 & 2,80 \\
\hline 0,98 & 65,74 & 66,71 & 31,55 & 33,31 & 22,53 & 24,14 & 2,24 & 2,73 \\
\hline 1,04 & 66,19 & 67,17 & 33,04 & 33,58 & 24,00 & 23,91 & 1,81 & 2,44 \\
\hline 1,10 & 66,22 & 66,17 & 33,16 & 33,88 & 24,17 & 25,33 & 2,06 & 2,54 \\
\hline 1,16 & 66,60 & 66,32 & 33,68 & 33,57 & 24,80 & 24,23 & 1,95 & 2,25 \\
\hline 1,22 & 66,78 & 66,35 & 33,16 & 33,33 & 24,41 & 24,24 & 1,89 & 2,34 \\
\hline Média & 66,15 & 66,58 & 32,72 & 33,22 & 23,77 & 23,97 & 2,05 & 2,52 \\
\hline \multicolumn{9}{|l|}{ Mean } \\
\hline Regressão & $\mathrm{L} * *$ & NS & $\mathrm{L}^{* *}$ & $\mathrm{Q}^{* *}$ & $\mathrm{~L}^{* *}$ & $\mathrm{Q}^{* *}$ & $\mathrm{~L}^{*}$ & $\mathrm{~L} * *$ \\
\hline Regression & & & & & & & & \\
\hline $\mathrm{CV}$ & \multicolumn{2}{|c|}{1,070} & \multicolumn{2}{|c|}{2,573} & \multicolumn{2}{|c|}{3,401} & \multicolumn{2}{|c|}{16,159} \\
\hline
\end{tabular}

$L^{*}$ - Efeito linear $(P<0,05),\left(L^{*}-\right.$ Linear effect $\left.[P<.05]\right)$.

$L^{* *}$ - Efeito linear $(P<0,01),\left(L^{* *}-\right.$ Linear effect $\left.[P<.01]\right)$.

$Q^{\star *}$ - Efeito quadrático $(P<0,01),\left(Q^{* *}-\right.$ Quadratic effect $\left.[P<.01]\right)$.

NS - Não significativo (Not significant).

M - Macho (Male), F - Fêmea (Female).

Tabela 5 - Estimativas das exigências de lisina e regressões para os rendimentos de carcaça, peito com osso, filé de peito e gordura abdominal de machos e fêmeas de corte, no período de 22 a 40 dias de idade

Table 5 - Estimates of lysine requirements and regressions for carcass, breast with bone, breast fillet yields and abdominal fat of males and females broiler chickens from 22 to 40 days of age

\begin{tabular}{|c|c|c|c|}
\hline & $\begin{array}{c}\text { Exigência }(\%) \\
\text { Requirement }\end{array}$ & $\begin{array}{l}\text { Regressão } \\
\text { Regression }\end{array}$ & $\mathrm{r}^{2}$ \\
\hline & & $1-21$ dias (days) & \\
\hline & & $\begin{array}{l}\text { Modelo quadrático } \\
\text { Quadratic model }\end{array}$ & \\
\hline \multicolumn{4}{|l|}{$\begin{array}{l}\text { Fêmea } \\
\text { Female }\end{array}$} \\
\hline $\begin{array}{l}\text { Peito com osso } \\
\text { Breast with bone }\end{array}$ & 1,109 & $Y=-37,7388+129,277 x-58,3047 x^{2}$ & 0,93 \\
\hline $\begin{array}{l}\text { Filé de peito } \\
\text { Breast fillet }\end{array}$ & 1,114 & $Y=-61,4748+154,954 x-69,5476 x^{2}$ & 0,80 \\
\hline
\end{tabular}

Modelo linear

Linear model

Macho

Male

\begin{tabular}{|c|c|c|c|}
\hline Carcaça & 1,220 & $Y=61,2122+4,61355 x$ & 0,97 \\
\hline Carcass & & & \\
\hline Peito com osso & 1,220 & $Y=25,5912+6,64686 x$ & 0,71 \\
\hline Breast with bone & & & \\
\hline $\begin{array}{l}\text { Filé de peito } \\
\text { Breast fillet }\end{array}$ & 1,220 & $\mathrm{Y}=15,879+7,44000 \mathrm{x}$ & 0,79 \\
\hline $\begin{array}{l}\text { Gordura abdominal } \\
\text { Abdominal fat } \\
\text { Fêmea } \\
\text { Female }\end{array}$ & 1,220 & $Y=3,57813-1,42579 x$ & 0,55 \\
\hline $\begin{array}{l}\text { Gordura abdominal } \\
\text { Abdominal fat }\end{array}$ & 1,220 & $Y=4,36357-1,72556 x$ & 0,80 \\
\hline
\end{tabular}


a suplementação de dietas com aminoácidos melhora a qualidade da carcaça (FANCHER e JENSEN, 1989), notadamente o rendimento do músculo do peito. Observa-se também uma carcaça mais úmida e magra, com maior teor de água e menos tecido adiposo.

Com relação à variável gordura abdominal, os resultados dos machos e das fêmeas estão de acordo com os obtidos por BAKER e MOLITORIS (1991), onde os mesmos verificam efeito linear com nível de lisina na ração na faixa de $1,20 \%$ e a deposição de gordura em torno de $1,00 \%$. No entanto, a exigência estimada para os machos através da regressão foi de $1,22 \%$ de lisina total, enquanto que para as fêmeas houve variação de 0,98 a $1,22 \%$ de lisina.

Levando em consideração todos os parâmetros analisados (desempenho, avaliação de carcaça e gordura abdominal), durante a fase de 22 a 40 dias, pode-se estimar uma exigência de 1,164 e 1,143\% de lisina total, o que corresponde a 1,044 e 1,023\% de lisina digestível, para machos e fêmeas, respectivamente.

\section{Conclusões}

De acordo com os resultados de desempenho e de carcaças obtidos nas diferentes fases de criação da linhagem Ross, estimaram-se exigências de 1,303 e $1,164 \%$ de lisina total e 1,183 e $1,044 \%$ de lisina digestível, para frangos de corte machos e de 1,249 e $1,143 \%$ de lisina total e 1,129 e $1,023 \%$ de lisina digestível, para frangos de corte fêmeas, nas fases de 1 a 21 e 22 a 40 dias, respectivamente.

\section{Agradecimento}

\section{À Ajinomoto Biolatina - São Paulo (SP).}

\section{Referências Bibliográficas}

BAKER, D. H., MOLITORIS, B.A. 1991. Partioning of nutrients for growth and other metabolic functions: efficiency and priority considerations. Poult. Sci., 70:1797-1805.

BARBOSA, M.J.B., JUNQUEIRA, O.M., ARAÚJO, L.F. et al. Avaliação do desempenho de frangos de corte submetidos a diferentes níveis de treonina e lisina na fase final de criação. Campinas, 1998. Anais... Campinas, FACTA, 1998. p.30.

BARBOZA, W.A. e ROSTAGNO, H.S. Exigências nutricionais de lisina para frangos de corte no período de 1 a 21 dias de idade. In: REUNIÃO ANUAL DA SOCIEDADE BRASILEIRA DE ZOOTECNIA, v.4, 1998, Botucatu, Anais... Botucatu:SBZ, 1998a. p.499-501.

BARBOZA, W.A., ROSTAGNO, H.S. Exigências nutricionais de lisina para frangos de corte no período de 22 a 40 dias de idade. In: REUNIÃO ANUAL DA SOCIEDADE BRASI-
LEIRA DE ZOOTECNIA, v.4, 1998, Botucatu, Anais... Botucatu:SBZ, 1998b. p.505-507.

BERCOVICI, D. 1998. Nutrição Protéica de Frangos de Corte. In: SIMPÓSIO SOBRE NUTRIÇÃO ANIMAL E TECNOLOGIA DA PRODUÇÃO DE RAÇÕES, 1998, Campinas, SP. Anais... Campinas: CBNA, 1998. p.39-49.

BILGILI, S.F., MORAN JR, E.T., ACAR, N. 1992. Strain cross response of heavy male broilers to dietary lysine in the finisher feed: live performance and further-processing yields. Poult. Sci., 71:850-858.

CABEL, M.C., GOODWIN, T.L., WALDROUP, P.W. 1988. Feather meal as a nonspecific nitrogen source for abdominal fat resuction in broiler during the finishing period. Poult. Sci., 67:300-306.

CABEL, M.C., WALDROUP, P.W. 1991. Effect of dietary protein level and lenght of feeding on performance and abdominal fat content of broiler chickens. Poult. Sci., 70:1550-1558.

COLNAGO, G.L., JENSEN, L.S. 1992. Putrescine effects on performance of male broiler chicks fed low-protein diets supplemented with essencial amino acids. Poult. Sci., 71:211-214.

CONHALATO, G.S. Exigência de lisina digestível para frangos de corte machos. Viçosa: UFV, 1998. 79p. Dissertação (Mestrado em Zootecnia) - Universidade Federal de Viçosa, 1998.

FANCHER, B., JENSEN, L.S. 1989. Influence on performance of three to six-week old broilers of varying dietary protein contents with supplementation of essencial amino acid requirements. Poult. Sci., 68:113-123.

HAN, Y., BAKER, D.H. 1991. Lysine requirements of fast-andslow grossing broiler chicks. Poult. Sci., 70:2108-2114.

HAN, Y., BAKER, D.H. 1992. Effects of heat stress, sex and body weight on responses of broiler chicks to dietary lysine. Poult. Sci., 71:37. (Suplemento 1)

HAN, Y., BAKER, D.H. Digestible lysine requirement of male and female broiler chicks during the period three to six weeks posthatching. Poultry Science, v.73, p.1739-1745, 1994.

HICKLING, D., GUENTER, M., JACKSON, M.E. 1990. The effect of dietary methionine and lysine on broiler chicken performance and breast meat yield. Can. J. Anim. Sci., 70:673-678.

HOLSHEIMER, J.P., VEERKAMP, C.H. 1992. Effect of dietary energy and lysine content on performance and yields of two strains of males broiler chicks. Poult. Sci., 71:872-879.

KIDD, M.T., KERR, B.J., ANTHONY, N.B. 1997. Dietary interactions between lysine and threonine in broilers. Poult. Sci., 76:608-614.

KNOWLES, T.A., SOUTHERN, L.L., ROBBINS, K.R. 1997. The use of serum urea nitrogen concentrations for the determination of lysine requirements of gilts. Prof. Anim. Sci., 13:65-69.

LECLERCQ, B. 1998. Specific effects of lysine on broiler production: comparison with threonine and valine. Poult. Sci., 77:118-123.

LIMA, I.L. Níveis nutricionais utilizados nas rações pela indústria avícola. In: SIMPÓSIO INTERNACIONAL SOBRE EXIGÊNCIAS NUTRICIONAIS DE AVES E SUÍNOS, 1996, Viçosa. Anais... Viçosa: UFV, 1996.

MACK, S., BERCOVICI, D., DE GROOTE, G. et al. 1999. Ideal amino acid profile and dietary lysine specification for broiler chickens of 20 to 40 days of age. Br. Poult. Sci., 40:257-265.

MORAN JR., E.T., BILGILI, S.F. 1990. Processing losses, carcass quality and meat yields for broiler chicken, receiving diets marginally deficient to adequate in lysine prior to marketing. Poult. Sci., 69:702-710. 
NATIONAL RESEARCH COUNCIL - NRC. 1994. Nutrient requirements of poultry. 9.ed. Washington, D.C.: National Academy Press. 155p.

REZENDE, J.A.A., ROSTAGNO, H.S., SILVA, M.A. et al. 1980. Níveis de proteína, aminoácidos sulfurosos e lisina em rações de frangos submetidos a regime de alta temperatura. Fase inicial. R. Soc. Bras. Zootec., 9(1):90-107.

ROSTAGNO, H.S., PACK, M. Growth and breast meat responses of different broiler strains to dietary lysine. In: EUROPEAN SYMPOSION POULTRY NUTRITION, 10, 1995, Antalya, Turkey. Proceedings... Antalya, 1995. p.260-262.

ROSTAGNO, H.S. BARBARINO JR., P., BARBOSA, W.A. Exigências nutricionais das aves determinadas no Brasil. In: SIMPÓSIO INTERNACIONAL SOBRE EXIGÊNCIAS NUTRICIONAIS DE AVES E SUÍNOS, Viçosa, MG, 1996. Anais... UFV: DZO, 1996. p.361-388.

ROSTAGNO, H.S., ALBINO, L.F.T., DONZELE, J.L. et al. 2000. Tabelas brasileiras para aves e suínos: composição de alimentos e exigências nutricionais. Viçosa, MG: UFV. 141p.

SCHEURMANN, G.N., MAIER, J.C., BELLAVER, C. Exigência de lisina para frangos de corte na fase de 21 a 42 de idade. In: REUNIÃO ANUAL DA SOCIEDADE BRASILEIRA DE ZOOTECNIA, 30, Rio de Janeiro, RJ. Anais... Rio de Janeiro: SBZ, 1993. p.314.
SIBBALD, I.R., WOLYNETZ, M.S. 1986. Effects of dietary lysine and feed intake on energy utilization and tissue synthesis by broiler chicks. Poult. Sci., 65:98-105.

SUMMERS, J.D., LEESON, S. 1985. Broiler carcass composition as affected by amino acid supplementation. Can. J. Anim. Sci., 65:717-723.

UNIVERSIDADE FEDERAL DE VIÇOSA - Central de Processamento de Dados UFV-CPD. SAEG 7.1 - Sistema para análise estatística e genética. Viçosa: 1997. 59p.

WALDROUP, P.W. 1991. Dietary nutrients allowances for chickens and turkeys. Feedstuffs, 63(29):77.

WALDROUP, P.W., MITSHELL, R.J., PAYNE, J.R. et al. 1976. Performance of chicks fed diet formulated to minimize excess levels of essential amino acids. Poult. Sci., 55:243-253.

Recebido em: $24 / 11 / 00$

Aceito em: 23/05/01 